\title{
Estrutura de estádios ontogenéticos em população nativa da palmeira Syagrus romanzoffiana (Cham.) Glassman (Arecaceae) ${ }^{1}$
}

\author{
Luís Carlos Bernacci' ${ }^{2,4}$, Fernando Roberto Martins ${ }^{3}$ e Flavio Antonio Maës dos Santos ${ }^{3}$
}

Recebido em 11/09/2006. Aceito em 8/05/2007

\begin{abstract}
RESUMO - (Estrutura de estádios ontogenéticos em população nativa da palmeira Syagrus romanzoffiana (Cham.) Glassman (Arecaceae)). O jerivá tem importância ecológica e econômica, inclusive palmito de qualidade. Para conhecer características básicas do ciclo de vida desta espécie, estudou-se a população na floresta paludícola da Reserva Santa Genebra (Campinas, SP). Observações e medições foram feitas em 100 parcelas $(5 \times 5 \mathrm{~m})$ e sub-parcelas $(2 \times 2 \mathrm{~m})$ aleatórias, dentro de uma área de 1 ha, realizadas novamente após $400 \pm 3$ dias. Foram reconhecidos seis estádios ontogenéticos, distinguíveis no campo: plântula (folha inteira estreita), juvenil fase 1 (folha inteira, largura $\geq 2 \mathrm{~cm}$ ), juvenil fase 2 (folha segmentada), imaturo (folha segmentada e estipe aéreo), virgem (estipe aéreo e raízes caulígenas) e reprodutor (raízes caulígenas e presença periódica de estruturas reprodutivas). Para o reconhecimento das plântulas usaram-se características foliares, pois o momento da independência trófica não pôde ser determinado no campo, tendo, o estádio, longa existência sob a baixa luminosidade do sub-bosque. Ocorreu sobreposição de tamanhos e na produção de folhas, embora houvesse diferenças significativas, pelo menos entre alguns estádios. As estruturas e propriedades adquiridas ou perdidas em cada estádio representariam vantagens adaptativas sob circunstâncias diferentes durante a ontogenia do jerivá, como a germinação remota, que pode ajudar a explicar a ampla ocorrência da espécie, incluindo áreas mais secas, e raízes caulígenas, por melhorar a fixação e nutrição previamente à reprodução, na floresta paludícola.
\end{abstract}

Palavras-chave: população estruturada por estádios, fragmento florestal, Mata Atlântica, floresta paludícola, Brasil

\begin{abstract}
Structure of ontogenetic stages in a native population of the palm Syagrus romanzoffiana (Cham.) Glassman (Arecaceae)). Syagrus romanzoffiana is ecologically and economically important, including the production of good-quality hearts of palm. Aiming to describe this plant's basic life cycle, we studied a natural population in the swamp forest at the Santa Genebra Reserve, Campinas municipality, São Paulo state. Observations and measurements were made, and repeated after $400 \pm 3$ days, in 100 randomly located plots $(5 \times 5 \mathrm{~m})$ and sub-plots $(2 \times 2 \mathrm{~m})$, in an area of 1 ha. Six ontogenetic stages were recognized: seedling (narrow entire leaf), juvenile phase 1 (entire leaf, width $\geq 2 \mathrm{~cm}$ ), juvenile phase 2 (segmented leaf), immature (segmented leaf, aerial stem), virgin (aerial stem, cauligenous roots), and reproductive (cauligenous roots and periodic presence of reproductive structures). Since the moment of trophic independence could not be determined in the field, leaf characteristics were used to identify seedlings. Seedlings live for a long time in the low light of the understory. Even though significant differences could be observed, size and leaf production overlapped among different stages. Remote germination, used to explain the widespread occurrence of the species even in dry regions, and cauligenous roots that improve fixation and nutrition previous to reproduction in swamp forests, are morphological structures and properties acquired or lost in each stage that may represent adaptive advantages under different circumstances during ontogeny of S. romanzoffiana.
\end{abstract}

Key words: stage-structured population, forest fragment, Atlantic Forest, swamp forest, Brazil

\section{Introdução}

O ciclo de vida dos indivíduos em uma população consiste de uma série de estádios morfologicamente reconhecíveis, produzidos um após o outro até a morte e caracterizados pela aquisição e/ou perda de certas estruturas e propriedades, além de várias mudanças morfológicas, anatômicas, fisiológicas e bioquímicas que ocorrem durante a ontogenia (Gatsuk et al. 1980).
Assim, um indivíduo poderia ser caracterizado em cada momento de sua vida não só por sua idade cronológica, como também por critérios biológicos típicos de certo intervalo de seu desenvolvimento, que é chamado estádio ontogenético (Carvalho et al. 1999).

O uso de estádios ontogenéticos para abordar a estrutura da população permite contornar o difícil problema de determinar a idade das plantas (Manly 1990). A duração média de cada estádio ontogenético

\footnotetext{
Parte da tese de Doutorado do primeiro Autor

2 Instituto Agronômico - IAC, NPD Jardim Botânico, CEC, C. Postal 28, 13001-970 Campinas, SP, Brasil

3 Universidade Estadual de Campinas, Departamento de Botânica, C. Postal 6109, 13081-970 Campinas, SP, Brasil

4 Autor para correspondência: bernacci@iac.sp.gov.br
} 
em cada espécie de planta é fixada geneticamente, mas, como as condições ambientais podem variar grandemente no tempo e no espaço, diferentes indivíduos podem atingir um mesmo estádio ontogenético com diferentes idades cronológicas (Gatsuk et al. 1980).

Assim, o estudo da estrutura de estádios ontogenéticos de uma população de plantas fornece muito mais informações com significado ecológico do que o estudo de sua estrutura etária (Silvertown \& Doust 1993). Adicionalmente, as plantas têm um mecanismo de regulação interna que percebe as condições ambientais e, em função delas, aceleram ou retardam seu desenvolvimento (Lawson \& Poethig 1995). Esse mecanismo seria independente do tamanho e da idade da planta, regulando sua morfogênese em cada estádio ontogenético, de modo diferente em cada espécie.

A sequiência de estádios ontogenéticos é um dos aspectos mais evidentes da história de vida de uma população, e esta é manifestada através do padrão de crescimento, diferenciação, acúmulo de reservas e, especialmente, reprodução de seus indivíduos, sendo a variação de tamanho um dos traços morfológicos mais conspícuos na seqüência dos estádios ontogenéticos (Begon et al. 1996).

A existência de um controle genético das propriedades, características e duração de cada estádio ontogenético e de sua seqüência no tempo indicam que sua expressão fenotípica é o resultado de ações seletivas durante um tempo evolutivo. A ocorrência de mudanças, geralmente discretas, entre diferentes estádios ontogenéticos faz supor que as pressões seletivas sejam diferentes em cada estádio. Inversamente, a ocorrência de diferentes fenótipos em diferentes estádios indica que cada um deles apresenta vantagens adaptativas mais ou menos específicas na superação de diferentes limitações impostas pelo ambiente, durante o desenvolvimento ontogenético (Lawson \& Poethig 1995). Plantas individuais de diferentes estádios ontogenéticos geralmente não têm propriedades ecológicas similares e, assim, podem explorar recursos e sofrer a ação de fatores de modos diferentes (Gatsuk et al. 1980).

A utilização de estádios ontogenéticos tem se difundido na atualidade, tanto no estudo de palmeiras (Durán \& Franco 1992; Svenning 2002; Freckleton et al. 2003; Souza et al. 2003; Souza \& Martins 2005, entre outros) como de plantas de outros grupos (desde ervas a árvores dicotiledôneas - Knevel \& Lubke 2004 e Marie-Pierre et al. 2006, respectivamente).
O objetivo deste estudo foi identificar e descrever os estádios ontogenéticos de uma população natural de uma espécie de palmeira arborescente e discutir o possível significado adaptativo das características de cada estádio. Para tanto, admitimos que cada estádio ontogenético possa ser caracterizado por caracteres macromorfológicos externos (tipos, número e tamanho das estruturas) e por certas propriedades (capacidade de produzir ou taxa de produção de certas estruturas). Também admitimos que a alteração dos caracteres macromorfológicos externos e das propriedades, que marca a transição de um estádio para outro, pode conferir à planta capacidade de sobreviver e crescer sob condições ambientais diferentes das existentes antes de apresentar estes caracteres macromorfológicos e/ou propriedades.

\section{Material e métodos}

Sítio amostral e espécie estudada - A Reserva Municipal de Santa Genebra (22 48'34"' 50'13''S e $47^{\circ} 06^{\prime} 15^{\prime}$ - $07^{\prime} 33^{\prime \prime} \mathrm{W}$ ) tem cerca de 250 ha e localiza-se no distrito de Barão Geraldo, município de Campinas, estado de São Paulo, Brasil. A floresta estacional semidecídua é a vegetação predominante e a floresta paludícola cobre $15 \%$ da área (Leitão Filho 1995). A temperatura média anual é de $20,3^{\circ} \mathrm{C}\left(22,7^{\circ} \mathrm{C}\right.$ no verão e $17,4{ }^{\circ} \mathrm{C}$ no inverno) e a precipitação média anual é de $1409,5 \mathrm{~mm}$, sendo que o período mais chuvoso inclui a primavera e o verão (Mello et al. 1994). Na Reserva, as altitudes variam de 585 a 616 m (São Paulo 1981) e o relevo é predominantemente plano a suave ondulado, enquanto na área paludosa, o relevo é ondulado, com declividade variando de 6 a 9\% (Jener F.L. Moraes IAC, comunicação pessoal). De acordo com o sistema da EMBRAPA (1999), o solo é Gleissolo Háplico eutrófico textura média a argilosa (Unithal Laboratório Agroquímico, Campinas, SP/Hélio do Prado - IAC, comunicação pessoal).

Na floresta paludícola da Reserva, ocorrem três espécies de palmeiras: Geonoma brevispatha Barb.Rodr., Euterpe edulis Mart. e Syagrus romanzoffiana (Cham.) Glassman. Esta última é a única palmeira emergente na floresta paludícola, sobressaindo além do dossel, a cerca de 20-25 m de altura e apresentando grande abundância (Toniato et al. 1998). Seus frutos são importantes para a dieta de frugívoros locais, como o esquilo-caxinguelê Sciurus ingrami (Galetti 1995).

O gênero Syagrus (Arecaceae) é endêmico da América do Sul, tem centro de diversidade entre os 
estados brasileiros da Bahia e Minas Gerais, é constituído por cerca de 42 espécies e oito híbridos naturais, dos quais sete inter-específicos e um intergenérico (Noblick 1996).

Syagrus romanzoffiana (jerivá) é a espécie com a distribuição mais ampla do gênero, ocorrendo desde a Bolívia e o estado brasileiro da Bahia até o Uruguai e Argentina, sendo mais abundante no sul e leste do Brasil (Glassman 1987). Por ser altamente decorativa e apresentar facilidade de transplante quando adulta, S. romanzoffiana é a palmeira mais usada na arborização de ruas e avenidas em todo o Brasil (Lorenzi 1992; Lorenzi et al. 1996) e também em muitos outros países (Graf 1986). É usada em construções rústicas, pois sua madeira é moderadamente pesada, dura e altamente durável (Lorenzi 1992). Produz palmito de boa qualidade e sabor ligeiramente amargo (Corrêa 1969), sendo uma das espécies indicadas para a produção deste alimento (Instituto Agronômico 1997; Bovi 1998). É planta apícola, fornecendo pólen e néctar para Apis mellifera L., Tetragonisca angustula Latreille e Trigona sp., entre outras espécies (Siqueira 1989; Souza et al. 1994). A polpa do fruto é comestível e apreciada pelo homem, por suínos e outros animais (Sanchotene 1989), os frutos e as folhas servem como alimento para o gado (Bondar 1964) e as brácteas são usadas em artesanato (L. Noblick, Fairchild Tropical Botanic Garden, comunicação pessoal). A semente apresenta de $25 \%$ a 52\% de gordura (Nogueira \& Machado 1950).

Terminologia de folhas - A terminologia para os tipos foliares seguiu Tomlinson (1960b), segundo o qual, eofilo se refere às primeiras folhas pós-cotiledonares com lâmina expandida, podendo ser inteiro, bífido ou segmentado. Depois que um ou mais eofilos (do mesmo formato que o primeiro) são produzidos, a planta produz uma longa série de folhas segmentadas transicionais (metafilos) cada vez mais complexas, até atingir o tipo de folha característico das plantas adultas (nomofilo). Este processo pode ser classificado em seis tipos básicos, relacionados à posição filogenética da espécie.

Estádios ontogenéticos e análise dos dados - Para o reconhecimento e a denominação dos estádios ontogenéticos, seguimos as recomendações e conceitos de Gatsuk et al. (1980). O ciclo de vida da planta é dividido em períodos, estes em estádios e estes em fases, sendo que, para o levantamento dos dados, utilizamos uma área delimitada por dois eixos ortogonais de 100×100 m, na região da nascente do Córrego do Quilombo, na qual 100 parcelas de $5 \times 5 \mathrm{~m}$ haviam sido localizadas através de sorteio de pares de números aleatórios. Em cada parcela, delimitamos uma subparcela de $2 \times 2 \mathrm{~m}$, na qual todos os indivíduos de todos os tamanhos foram amostrados. No restante da área de cada parcela de $5 \times 5 \mathrm{~m}$, apenas indivíduos com estipe foram amostrados. O período de estudo foi de março a outubro/1993 e de abril a novembro/1994 e cada planta presente nas parcelas e sub-parcelas foi medida num intervalo de $400 \pm 3$ dias entre a primeira e a última observação.

Na caracterização dos estádios, foram utilizados aspectos macro-morfológicos externos de cada planta, como: a) número de folhas vivas; b) partição do limbo foliar, podendo ser inteiro, pinatissecto ou transicional (parte distal pinatissecta e parte proximal inteira, em diferentes proporções); c) presença ou ausência de estipe aéreo; d) presença ou ausência de raízes caulígenas aéreas (raízes adventícias na base do estipe, Font-Quer 1985). Também foram utilizadas certas propriedades, como número de folhas produzidas no período de estudo e produção ou não de flores e frutos. Para estimar a produção de folhas durante o período de observação, a folha mais nova de cada planta foi marcada com uma fita colorida em 1993 e o número de folhas ulteriores à folha marcada foi contado em 1994. A folha mais nova foi considerada como aquela em que pelo menos $25 \%$ da lâmina estivessem distendidos. Para caracterizar o estádio de plântula e determinar sua dependência das reservas da semente, foram colhidas, fora das parcelas, 20 plantas com eofilos inteiros e estreitos (desde recém-germinadas até cerca de 10-15 cm), que foram cultivadas em casa de vegetação e acompanhadas, utilizando-se vermiculita como substrato, para facilitar as observações.

O tamanho de cada planta foi estimado através das seguintes variáveis: 1) diâmetro basal medido no nível do solo (se houvesse estipe com raízes caulígenas, também era medido o diâmetro do estipe logo acima delas); 2) altura da planta, medida verticalmente do solo até a altura máxima da copa; 3) comprimento do estipe, medido do solo até o ponto de inserção da bainha da folha mais baixa; 4) comprimento da nervura principal das duas folhas mais novas (para plantas com até $3 \mathrm{~m}$ de altura). Médias, desvios padrões e coeficientes de variação foram calculados de acordo com os procedimentos usuais (Sokal \& Rohlf 1979). 


\section{Resultados e discussão}

Os caracteres macro-morfológicos mais conspícuos observados durante o estudo permitiram distinguir seis categorias de plantas na população. Essas categorias foram consideradas como indicadoras de diferentes períodos, estádios e fases ontogenéticos. O período latente é representado pelo estádio de semente (Fig. 1), que não foi caracterizado no presente estudo. No período pré-reprodutivo reconheceram-se os estádios e fases de plântula (Fig. 2-4), juvenil fase 1 (Fig. 5), juvenil fase 2 (Fig. 6-7), imaturo (Fig. 8-9) e virgem (Fig. 10). Não observamos diferentes estádios no período reprodutor (Fig. 11) nem um período pósreprodutor na população estudada. Cada período, estádio ou fase reconhecida apresentou características macromorfológicas facilmente distinguíveis no campo (Tab. 1).

No presente estudo, as plântulas foram reconhecidas, no campo, a partir da emissão do primeiro eofilo (Fig. 3). A presença de estruturas embrionárias e nutrição dependente da semente caracterizam o estádio plântula (Gatsuk et al. 1980), entretanto, observações, em casa de vegetação, indicaram que a estrutura de ligação entre a plântula e a semente se deteriora por ocasião da produção do segundo eofilo. Ou seja, as menores plântulas se encontravam ligadas aos restos do fruto e semente (Fig. 3) e tinham eofilos estreitos (largura $<2 \mathrm{~cm}$ ), mas esta ligação estava ausente nas plântulas maiores, embora ainda com eofilo estreito (Fig. 4).

A existência de indivíduos com folhas inteiras mais largas (Fig. 5) chamou nossa atenção no campo, e, a partir de medições exploratórias, observou-se que estas folhas mais largas tinham $2 \mathrm{~cm}$ ou mais de largura, enquanto as folhas visualmente mais estreitas tinham menos do que $2 \mathrm{~cm}$ de largura. Através das observações realizadas em casa de vegetação, constatou-se que todos os indivíduos com eofilos inteiros largos não possuíam ligação com a semente (Fig. 5). Entretanto, como o cotilédone é sempre subterrâneo, não foi possível verificar, no campo, quando a planta deixa de usar as reservas da semente e assume total autonomia nutricional, ou seja, quando deixa de ser plântula, no conceito de Gatsuk et al. (1980). Assim, como não foi possível estabelecer claramente o tamanho em que ocorreu total autonomia trófica, todas as plantas de Syagrus romanzoffiana apenas com folhas inteiras estreitas foram incluídas no estádio de plântula, aqui caracterizado pelo ganho paulatino de autonomia trófica. Os indivíduos de eofilo largo (largura maior ou igual a $2 \mathrm{~cm}$ ) foram considerados como constituindo o estádio juvenil, fase 1 (Fig. 5).

Apesar da independência trófica ser a melhor alternativa para indicar o limite do estádio plântula, usar essa característica não é praticável, nos estudos ecológicos (Fenner 1987). Em nosso caso, foram considerados como plântulas todos os indivíduos com folha inteira $<2 \mathrm{~cm}$ de largura, ou seja, aqueles que podiam apresentar dependência trófica da semente. Em vista das diferenças morfológicas entre plântulas de diferentes espécies, é importante que os critérios para caracterizar o estádio plântula sejam claramente definidos em cada estudo (Fenner 1987).

Durante a germinação de Syagrus romanzoffiana, o cotilédone nunca se expande como uma lâmina verde e fotossintetizante e sempre fica parcialmente ou completamente subterrâneo. Esse tipo de germinação é chamado hipogeal (Tomlinson 1960a; b; Moore \& Uhl 1973) e caracteriza as palmeiras, exceto Nypa fruticans van Wurmb., que apresenta viviparidade (Tomlinson 1971; Moore \& Uhl 1973). Durante a germinação de $S$. romanzoffiana, a plântula se afasta do fruto devido ao alongamento do pecíolo e, principalmente, da bainha foliar do cotilédone. Esse tipo de desenvolvimento é chamado de germinação remota (Tomlinson 1960a; b; Moore 1961; Moore \& Uhl 1973). As diferenças na germinação entre as palmeiras podem ser devidas às particularidades do embrião (Gatin 1906 apud Tomlinson 1960a), à filogenia do grupo taxonômico ou à adaptação a tipos particulares de ambiente.

Syagrus romanzoffiana ocorre predominantemente em áreas de solo mais úmido (Lorenzi 1992; Bernacci et al. 1998); entretanto, é a espécie de mais ampla distribuição no gênero (Glassman 1987), chegando a ocorrer em áreas de cultivo recémabandonadas (Lorenzi 1992). A germinação remota, tal como observamos em $S$. romanzoffiana, pode ajudar a explicar esta ampla área de ocorrência da espécie, já que possibilita a penetração da plântula no solo, inclusive a sua gema apical, fornecendo resistência à dessecação.

A germinação remota pode ter significado adaptativo para palmeiras com distribuição em áreas sujeitas à seca (Tomlinson 1960a), ou em áreas afetadas por fogo ou outros distúrbios (Henderson et al. 1995). Entretanto, em outras palmeiras da Tribo Cocoeae (Uhl \& Dransfield 1987), como Attalea spp. (Henderson et al. 1995), Astrocaryum sciophilum (Sist 1989) e Syagrus sp. da Amazônia (Castro-dos-Santos 1981 

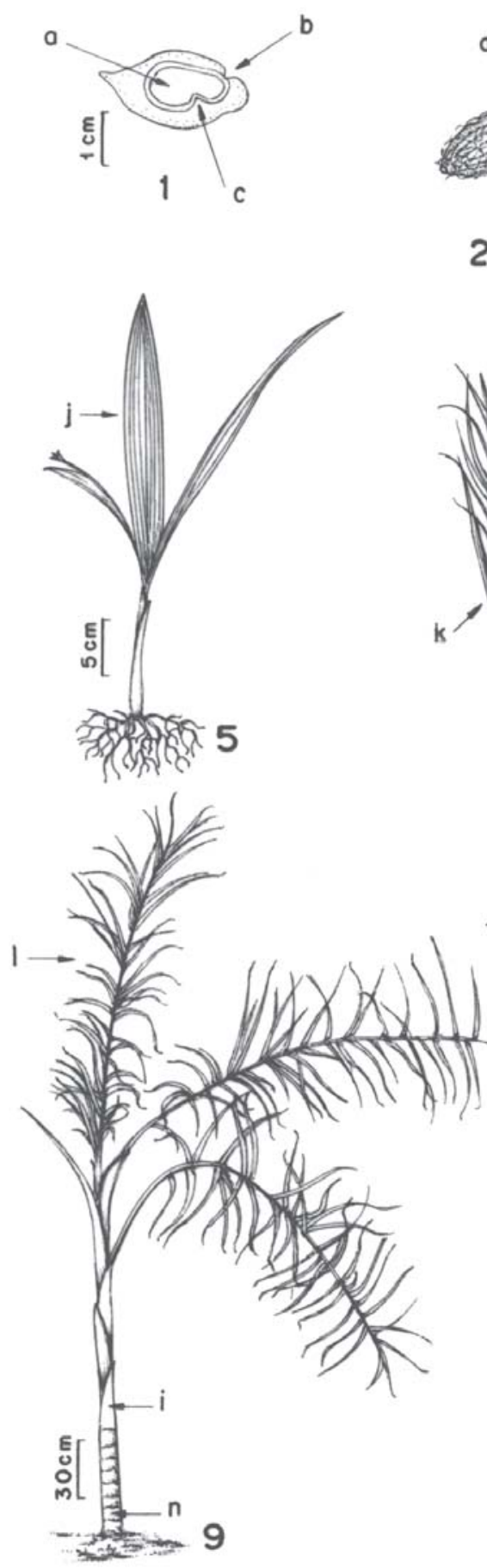
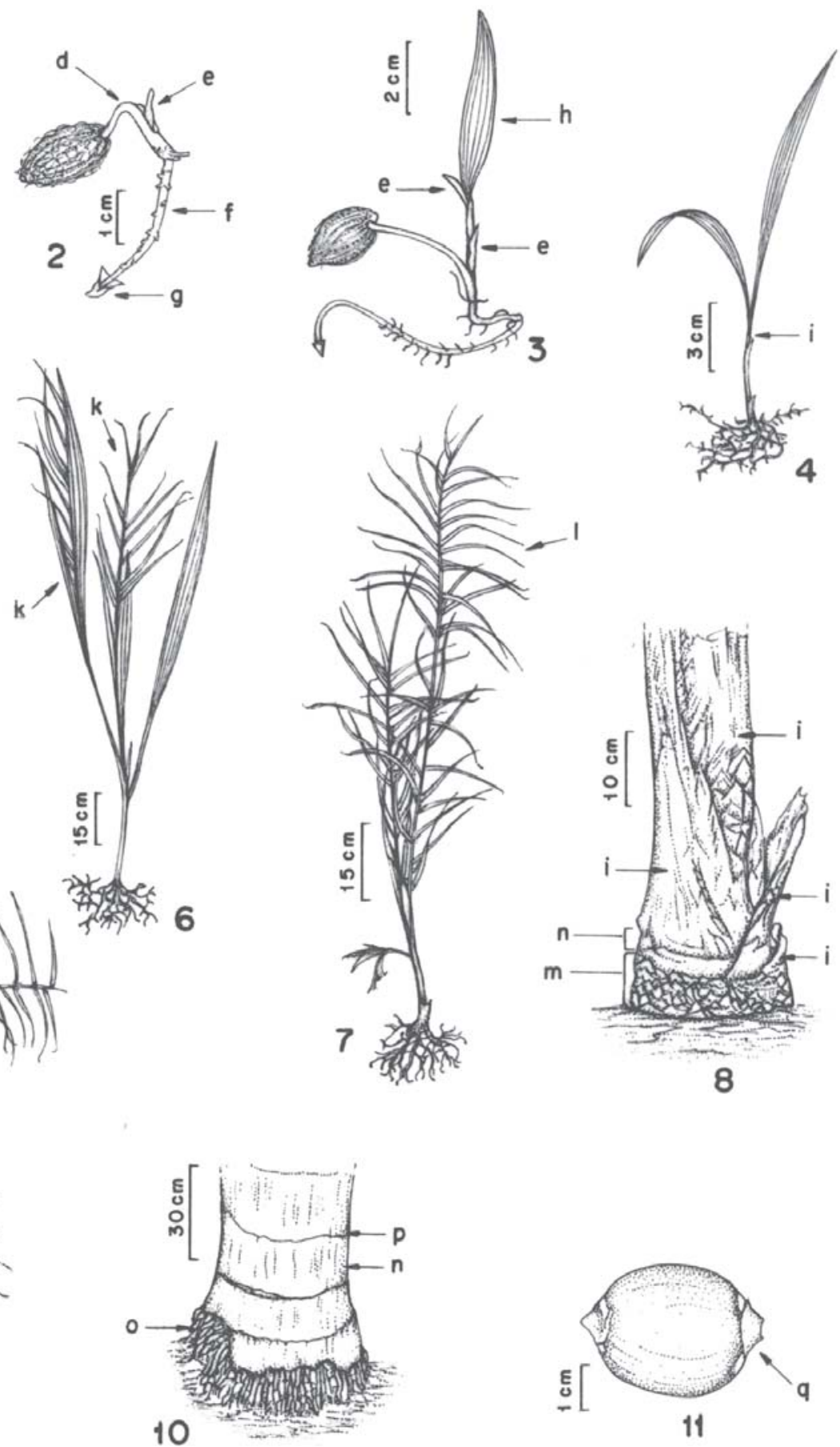

Figuras 1-11. Estádios ontogenéticos de Syagrus romanzoffiana (Cham.) Glassman, na floresta paludícola da Reserva Santa Genebra, Campinas, SP. Fruto: 1. Endocarpo em corte longitudinal, evidenciando a semente. Plântulas: 2. Emissão do coleoptile (bainha de proteção). 3. Emissão do primeiro eofilo. 4. Desligamento da semente e desenvolvimento de raízes. Juvenil, fase 1: 5. Os eofilos mais novos tornam-se largos ( $\geq 2 \mathrm{~cm}$ ). Juvenil, fase 2: 6. As folhas mais novas tornam-se semipinactessetas (metafilo). 7. As folhas mais novas tornam-se pinatissectas (nomofilo). Imaturo: 8. As bainhas basais caem e deixam o estipe visível. 9. Novos entrenós são produzidos e o estipe se alonga. Virgem: 10. Aparecem as raízes caulígenas; Reprodutor: 11. São produzidas as estruturas reprodutivas, que culminam no fruto. Sendo: a - semente; b - poro germinativo; c - gibosidade do endocarpo; d - pecíolo e bainha cotiledonares; e - coleoptile; f - raiz; $\mathrm{g}$ - coifa; $\mathrm{h}$ - eofilo; i - bainha foliar; j - eofilo largo ( $\geq 2 \mathrm{~cm})$; $\mathrm{k}$ - metafilo; 1 - nomofilo; $\mathrm{m}$ - região em que não é possível distinguir nó e entrenó; $\mathrm{n}$ - entrenó; o - raízes caulígenas; p - nó (cicatriz foliar); q - cálice persistente no fruto. 
Tabela 1. Períodos e estádios ontogenéticos pós-germinativos de Syagrus romanzoffiana (Cham.) Glassman e suas características macromorfológicas, na floresta paludícola da Reserva Santa Genebra, Campinas, SP. * - características distintivas.

\begin{tabular}{|c|c|c|c|c|c|}
\hline Períodos/estádios & $\begin{array}{l}\text { Largura da } \\
\text { lâmina }\end{array}$ & $\begin{array}{l}\text { Forma da } \\
\text { lâmina }\end{array}$ & Estipe aéreo & $\begin{array}{c}\text { Raízes caulígenas } \\
\text { aéreas }\end{array}$ & $\begin{array}{l}\text { Estruturas } \\
\text { reprodutivas }\end{array}$ \\
\hline \multicolumn{6}{|l|}{ A - Pré-reprodutivo } \\
\hline 1) plântula & estreita $(<2 \mathrm{~cm})^{*}$ & inteira & Ausente & ausentes & ausentes \\
\hline 2) juvenil fase 1 & $\operatorname{larga}(\geq 2 \mathrm{~cm})^{*}$ & inteira & Ausente & ausentes & ausentes \\
\hline 3) juvenil fase 2 & $\operatorname{larga}(\geq 2 \mathrm{~cm})$ & pinatissecta* & $\begin{array}{l}\text { ausente ou } \\
\text { coberto por bainhas } \\
\text { foliares }\end{array}$ & ausentes & ausentes \\
\hline 4) imaturo & $\operatorname{larga}(\geq 2 \mathrm{~cm})$ & pinatissecta & presente e visível* & ausentes & ausentes \\
\hline 5) virgem & $\operatorname{larga}(\geq 2 \mathrm{~cm})$ & pinatissecta & presente e visível & presentes* & ausentes \\
\hline B - Reprodutor & $\operatorname{larga}(\geq 2 \mathrm{~cm})$ & pinatissecta & presente e visível & presentes & $\begin{array}{c}\text { presentes* } \\
\text { periodicamente }\end{array}$ \\
\hline
\end{tabular}

apud Sist 1989), a germinação remota fixa a plântula a $40-50 \mathrm{~cm}$ de profundidade no solo, enquanto, na população estudada de Syagrus romanzoffiana, a plântula fica a apenas cerca de $5 \mathrm{~cm}$ distante dos remanescentes da semente, distância consideravelmente menor do que a dessas outras espécies.

A maioria das espécies de Syagrus ocorre em regiões relativamente secas ou áridas (Glassman 1987; Henderson et al. 1995) e não existem indicações de vantagem adaptativa para a presença de germinação remota em áreas úmidas. Assim, esta característica pode ser vestigial na população de Syagrus romanzoffiana estudada, embora, para a espécie como um todo, a presença deste tipo de germinação possa propiciar a sua sobrevivência em áreas mais secas, permitindo maior plasticidade ecológica. A ocorrência de $S$. romanzoffiana, a partir das margens de rios, contribui para ampliar as possibilidades de dispersão da espécie, seja pela fauna, que se concentra neste tipo de ambiente, seja pela própria água. Seria interessante examinar o tamanho do eixo entre a plântula e a semente em outras populações de S. romanzoffiana, notadamente naquelas ocorrentes em áreas mais secas, já que a capacidade da espécie ocupar ambientes variados indica a possibilidade de cultivo sob diversas condições, para buscar evidenciar diferenças decorrentes da história de vida de suas populações.

Em Syagrus romanzoffiana, a primeira folha fotossintetizante (eofilo) (Fig. 3) é inteira, sendo que eofilos produzidos posteriormente continuam inteiros (Fig. 4), ficando mais largos (Fig. 5) com o crescimento da planta. Posteriormente, inicia-se a segmentação da folha a partir do ápice, ficando a porção basal da lâmina foliar inteira e a porção apical segmentada (metafilos - Fig. 6). As folhas totalmente segmentadas (nomofilos - Fig. 7 e 9) são irregularmente pinatissectas e o segmento terminal confunde-se com a nervura principal.

No estádio juvenil fase 1 (Fig. 5), a planta de Syagrus romanzoffiana é independente das reservas da semente, conseguindo autonomia nutricional exclusivamente da atividade fotossintética. Além da independência nutricional da semente, as alterações observadas nos tipos de folhas foram utilizadas para reconhecer o estádio juvenil, considerando-se os indivíduos que apresentaram folhas em início de segmentação (Fig. 6) ou totalmente segmentadas (Fig. 7) como constituindo a fase 2 deste estádio. Em S. romanzoffiana, o estádio juvenil foi caracterizado como representando uma condição intermediária, em que características da plântula são paulatinamente perdidas, mas a planta ainda não tem características dos indivíduos maduros, tal como sugerido por Gatsuk et al. (1980) para o reconhecimento deste estádio.

A aquisição da forma definitiva da folha (nomofilo) é o principal evento que caracteriza o estádio juvenil em Syagrus romanzoffiana. Neste estádio a folha deixa de ser inteira e larga (fase 1), passando a pinatissecta (fase 2), com produção de folhas transicionais, parcialmente inteiras e parcialmente segmentadas. Em Welfia georgii, Socratea durissima, Iriartea gigantea (Vandermeer et al. 1974; Vandermeer 1990) e Euterpe edulis (D.M. Silva-Matos, Universidade Federal de São Carlos, comunicação pessoal), o estádio juvenil corresponde aos indivíduos sem estipe aéreo e com pelo menos uma folha pinatissecta.

Nossos dados sugerem que a passagem para o estádio juvenil pode demorar a ocorrer em Syagrus 
romanzoffiana, ou seja, o estádio plântula, tal como considerado aqui, pode ter longa duração, chegando a durar mais de 400 dias (período de coleta de dados no campo) e indicando que a plântula tem capacidade de sobreviver às condições de baixa luminosidade existentes no sub-bosque. Em Rhapidophyllum histrix (Pursh) H.A. Wendl. \& Drude, o estádio plântula (folhas inteiras) durou cerca de três anos e meio em casa de vegetação (Clancy \& Sullivan 1988), confirmando que, em geral, o desenvolvimento das palmeiras é lento desde a fase inicial (Lorenzi 1992).

De acordo com o princípio do desenho ótimo (Rosen 1967 apud Parkhurst \& Loucks 1972), organismos com forma e função otimizadas em relação a um ambiente particular têm sobrevivência, crescimento e reprodução favorecidos devido à seleção natural, ou seja, para sobreviver, crescer e atingir a etapa reprodutiva os organismos podem apresentar conformações que se adaptam ao seu ambiente. A produção de folhas maiores representa um custo metabólico mais alto para a planta (Parkhurst \& Loucks 1972; Chazdon 1986), sendo que a primeira fase do crescimento das palmeiras arborescentes estende-se desde a forma inicial da folha (eofilo), observada nas plântulas, até a forma final (nomofilo), observada em estádios subseqüientes, com necessidades progressivamente maiores de luz (Granville 1978 apud Kahn 1986).

No campo, observamos que quando parte de uma outra planta crescia acima de um juvenil (fase 1 ou 2) de Syagrus romanzoffiana e a sombreava, este indivíduo podia sofrer uma regressão, passando a produzir folhas inteiras estreitas em vez de inteiras largas ou inteiras largas em vez de pinatissectas. Assim, embora não tenhamos efetuado medições de luz e correlações com transições, esperamos que, em locais onde a luminosidade é insuficiente, as plantas continuem a produzir folhas estreitas, o que pode contribuir para a longa duração do estádio de plântula. Se a intensidade de luz continuar insuficiente, esperamos que as plantas nesta condição não passem ao estádio juvenil e venham a morrer dentro de um certo tempo. Esperamos também que, em locais bem iluminados, a transição de plântula para juvenil seja mais rápida que em locais menos iluminados.

Neste caso, o desenvolvimento do sistema foliar fotossintético de Syagrus romanzoffiana deve ocorrer apenas em ambientes em que a luminosidade seja suficiente para compensar os custos de sua produção, sendo que o aumento da área fotossintetizante através da produção de folhas inteiras largas possibilitaria seu crescimento e a produção de folhas pinatissectas. Apenas os indivíduos que conseguem produzir mais folhas largas (juvenil, fase 1) e elaboradas (juvenil, fase 2) têm possibilidade de sobreviver e eventualmente continuar seu desenvolvimento até os estádios seguintes na floresta.

O estádio imaturo (Fig. 8-9) é caracterizado pela presença do estipe aéreo, que se torna observável após a morte das folhas velhas e o desprendimento das bainhas foliares. $\mathrm{O}$ estádio virgem caracteriza-se pela presença de raízes caulígenas (Fig. 10). O período reprodutivo caracteriza-se pela presença periódica de estruturas reprodutivas, que culminam com a produção dos frutos e sementes (Fig. 11).

Em Syagrus romanzoffiana, a visualização do estipe através da queda das bainhas foliares basais é uma alteração muito conspícua. Assim, o desenvolvimento do estipe foi considerado como característico do estádio imaturo, da mesma forma como tem sido considerado em outras palmeiras (Welfia georgii, Socratea duríssima, Iriartea gigantea - Vandermeer et al. 1974; Vandermeer 1990 - e Euterpe edulis D.M. Silva-Matos, Universidade Federal de São Carlos, comunicação pessoal). A fase de elaboração do estipe corresponde à segunda fase de crescimento das palmeiras arborescentes, quando é necessária maior intensidade luminosa, o que ocorreria somente quando a palmeira alcançasse a luz solar direta, tal como em clareiras (Granville 1978 apud Kahn 1986). Em diversas espécies de palmeiras, de diferentes grupos taxonômicos, o desenvolvimento do estipe está associado a uma série de alterações anatômicas (Ghose \& Johri 1990). Portanto, a ocorrência da mesma seqüência de eventos em diferentes espécies de palmeiras arborescentes fortalece a interpretação de Granville (1978 apud Kahn 1986), do desenvolvimento de palmeiras arborescentes e a hipótese de que cada estádio apresenta diferentes vantagens adaptativas sob diferentes circunstâncias.

Os indivíduos do estádio virgem caracterizam-se por apresentar traços típicos das plantas adultas, mas ainda não apresentam capacidade de reprodução sexuada (Gatsuk et al. 1980), sendo que, morfologicamente, em Syagrus romanzoffiana distinguem-se dos imaturos por apresentarem raízes caulígenas.

As raízes caulígenas podem estar associadas ao aumento de absorção de nutrientes e da capacidade de fixação mecânica da planta, além de aumentarem o espaço ocupado pela planta e pela população ao nível do solo. Maior espaço ocupado implica em maior acesso a recursos e sucesso frente a competidores, 
pressões que também podem favorecer indivíduos com raízes caulígenas aéreas. A pequena quantidade de oxigênio disponível em solos saturados hidricamente é outra pressão que poderia favorecer alterações morfoanatômicas que permitissem a difusão do oxigênio da atmosfera para o sistema radicular sub-superficial (Joly 1986). Na floresta paludícola estudada, é relativamente frequiente a queda de árvores de várias espécies por desenraizamento, evento não observado para Syagrus romanzoffiana durante o período de estudo. Uma boa fixação da planta no substrato é importante antes da aquisição de estruturas reprodutivas, que normalmente representam alto custo à planta e impõem uma aceleração lateral capaz de desestabilizar mecanicamente a palmeira (Niklas 1992).

Embora ambientes com umidade relativa do ar insuficiente possam impedir o desenvolvimento destas raízes aéreas, em algumas condições de cultivo (Luiz A.F. Matthes - IAC, comunicação pessoal), raízes caulígenas podem ser mais freqüentes em climas mais secos, tal como no município paulista de Monte Alto, do em climas menos secos, tal como nos indivíduos cultivados na arborização da cidade de Campinas. Assim, as raízes aéreas, observadas na floresta paludícola, podem ser decorrentes da história de vida daquelas palmeiras, ou seja, especialmente por se desenvolverem em terreno instável e com pequena quantidade de oxigênio disponível no solo, haveria pressão para uma melhor fixação das plantas no substrato, favorecendo indivíduos capazes de produzirem raízes caulígenas naquela população. Adicionalmente, o ambiente úmido da floresta paludícola não é limite à produção destas raízes.

Variações de tamanho, freqüentemente menos conspícuas que variações macromorfológicas, também corroboraram a classificação adotada para os estádios (Fig. 12). Para a caracterização do tamanho e sua variação em cada estádio, foram consideradas apenas as medidas tomadas em 1994, pois ocorreram poucas mudanças de estádio entre os indivíduos analisados. Foram analisados 766 indivíduos vivos, possibilitando distinguir três grupos de plantas, com base nas relações de diâmetro basal e altura. O primeiro grupo, com diâmetros até $7 \mathrm{~cm}$ e alturas até $3 \mathrm{~m}$, incluiu os indivíduos sem estipe aéreo ou com estipe aéreo coberto por bainhas foliares, de folhas inteiras ou pinatissectas, ou seja, plântulas e juvenis. O segundo grupo, com diâmetros entre $7 \mathrm{~cm}$ e $18 \mathrm{~cm}$ e alturas entre $3 \mathrm{~m}$ e $6 \mathrm{~m}$, incluiu os indivíduos imaturos, em que o desprendimento natural das bainhas foliares evidenciava o estipe acima do solo, sem raízes caulígenas aéreas. O terceiro grupo, com diâmetros e alturas maiores, incluiu os indivíduos com raízes caulígenas na base do estipe, ainda não reprodutivos (virgens) ou já reprodutivos. No terceiro grupo, os indivíduos menores corresponderam àqueles que não se reproduziram no período, enquanto os indivíduos maiores reproduziram-se. No entanto, ocorreu sobreposição de diâmetros e alturas entre esses indivíduos, não sendo possível distinguir apenas através do tamanho os indivíduos que se reproduziram dos que não se reproduziram.

Apesar de não existir sobreposição de tamanho apenas entre juvenil fase 2 e imaturo, em relação à altura e diâmetro basal (Fig. 12), o tamanho dos indivíduos aumentou continuamente durante o desenvolvimento ontogenético de Syagrus romanzoffiana (Tab. 2-5). As médias da altura vertical (Tab. 2) e do comprimento do estipe (Tab. 3) diferiram entre todos os estádios ontogenéticos. Apenas virgens e reprodutores mostraram diâmetro basal médio sem diferença estatisticamente significativa (Tab. 2). O número médio de folhas.indivíduo ${ }^{-1}$ só não diferiu entre as fases 1 e 2 do estádio juvenil, enquanto a taxa de
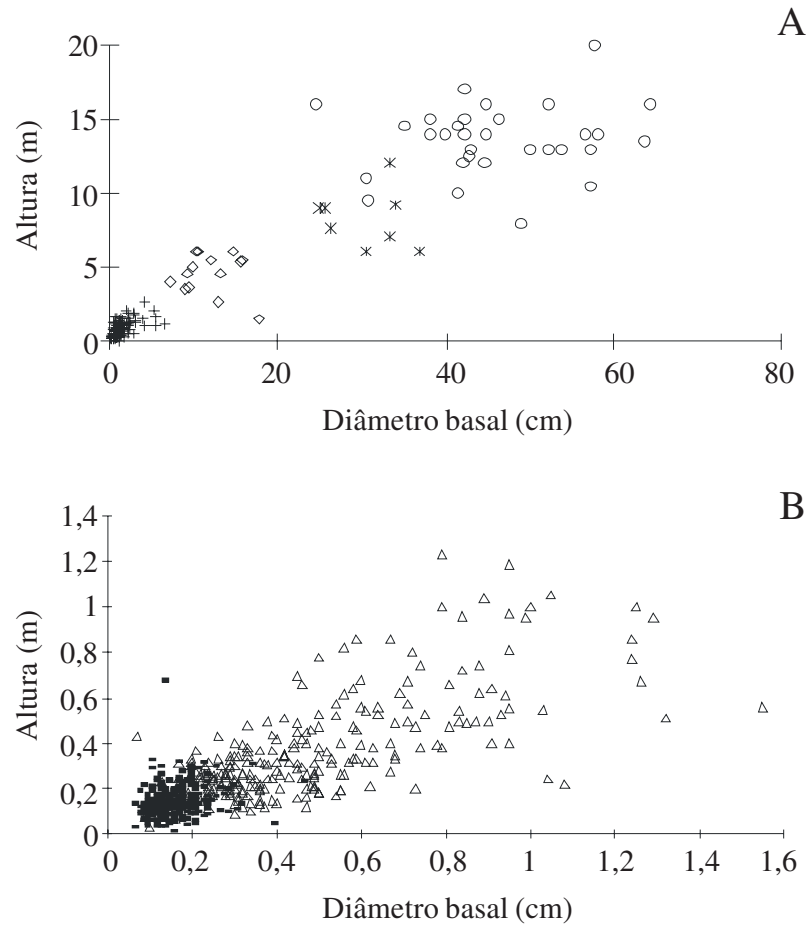

Figura 12. A. Diagrama de dispersão do diâmetro basal e altura de 766 plantas de Syagrus romanzoffiana (Cham.) Glassman, na área de floresta paludícola da Reserva Santa Genebra, Campinas, SP. B. Detalhe da Fig. 12A evidenciando plântula e juvenil 1. Sendo: - plântula; $\Delta$ juvenil 1 ; + juvenil 2; $\diamond$ imaturo; * virgem; $\mathrm{O}$ reprodutor. 
Tabela 2. Diâmetro basal e altura da planta, mínimo (mín.), máximo (máx.) e médio (méd.), erro padrão (ep), coeficiente de variação (cv) e número de observações (n), em Syagrus romanzoffiana (Cham.) Glassman, na floresta paludícola da Reserva Santa Genebra, Campinas, SP.

\begin{tabular}{|c|c|c|c|c|c|c|c|c|c|c|c|}
\hline \multirow[b]{2}{*}{ Estádios } & \multicolumn{5}{|c|}{ Diâmetro basal $(\mathrm{cm})$} & \multicolumn{5}{|c|}{ Altura da planta (m) } & \multirow[t]{2}{*}{$\mathrm{n}$} \\
\hline & mín. & máx. & méd. & ep & $\mathrm{cv}$ & mín. & máx. & méd. & ep & $\mathrm{cv}$ & \\
\hline Plântula & 0,06 & 0,46 & $0,15^{\mathrm{a}}$ & $3 \times 10^{-3}$ & 35,91 & 0,01 & 0,68 & $0,14^{\mathrm{a}}$ & 0,07 & 49,29 & 307 \\
\hline Juvenil 1 & 0,07 & 1,55 & $0,48^{\mathrm{b}}$ & 0,02 & 54,86 & 0,03 & 1,23 & $0,37^{\mathrm{b}}$ & 0,01 & 60,88 & 245 \\
\hline Juvenil 2 & 0,14 & 6,59 & $1,24^{\mathrm{c}}$ & 0,08 & 81,49 & 0,05 & 2,60 & $0,75^{\mathrm{c}}$ & 0,03 & 57,98 & 160 \\
\hline Imaturo & 7,08 & 17,83 & $12,03^{\mathrm{d}}$ & 0,80 & 24,88 & 2,65 & 6,00 & $4,86^{\mathrm{d}}$ & 0,28 & 21,68 & 14 \\
\hline Virgem & 24,83 & 36,92 & $30,68^{\mathrm{e}}$ & 1,49 & 13,73 & 6,00 & 10,00 & $7,73^{\mathrm{e}}$ & 0,50 & 18,37 & 8 \\
\hline Reprodutor & 24,51 & 64,30 & $46,36^{\mathrm{f}}$ & 1,68 & 20,51 & 8,00 & 20,00 & $13,45^{\mathrm{f}}$ & 0,42 & 17,52 & 32 \\
\hline
\end{tabular}

Letras iguais para média representam diferenças não significativas, teste Tukey, $\alpha=5 \%$

produção de folhas (folhas produzidas.indivíduos ${ }^{-1}$ ) foi muito variável entre os estádios, diminuindo em juvenil 2 , mas voltando a aumentar em virgens e reprodutores (Tab. 4). O comprimento médio das folhas foi diferente entre todos os estádios analisados (plântula, juvenil $1 \mathrm{e}$ 2 - Tab. 5).

Assim, além das características macromorfológicas, as medidas quantitativas podem ser utilizadas como auxiliares, complementando a distinção de estádios ontogenéticos em Syagrus romanzoffiana. Progressivamente, o tamanho necessário para passar ao estádio seguinte aumenta durante a ontogenia, sendo que o tamanho, notadamente a altura, tem sido utilizado como característica para estruturar populações de palmeiras (Bovi et al. 1988; Reis et al. 1996; Bernal 1998; Monteiro \& Fisch 2005).

Contudo, as plântulas, juvenis e imaturos pequenos de Syagrus romanzoffiana podem apresentar grandes diferenças de altura em um curto período de tempo, dependendo do grau de desenvolvimento da folha. A folha desenvolve-se levemente inclinada, quase na vertical,e a altura da planta (do solo até o ponto mais elevado das folhas) aumenta com o desenvolvimento da folha. Depois que a folha se distende totalmente, ela se inclina e a altura total da planta diminui, até que, pela produção de uma nova folha, a altura da planta pode tornar a aumentar. Nos imaturos grandes, virgens e reprodutores, quando os indivíduos estão mais expostos à luz, as folhas novas normalmente apresentam uma inclinação maior e não superam a altura das outras folhas. Alterações na posição da folha foram também observadas em outras espécies de palmeiras. Em Geonoma cuneata Wendl. ex Spruce e Asterogyne martiana Wendl. ex Burret (espécies de palmeiras do sub-bosque), a posição da folha muda de quase vertical, durante a expansão, para horizontal, quando expandida (Chazdon 1986). A disposição horizontal maximiza a interceptação de luz de cada folha individualmente e da copa como um todo (Chazdon 1986).

Neste caso, quando a planta é jovem, a altura pode não ser uma indicação do seu desenvolvimento, devido à alteração da orientação das folhas, quando outras características podem apresentar resultados melhores. Por exemplo, em Syagrus romanzoffiana, virgens distinguem-se dos imaturos por terem altura, diâmetro basal (Tab. 2) e do estipe (Tab. 3) maiores; o número médio de folhas por planta foi maior no estádio juvenil

Tabela 3. Diâmetro e comprimento do estipe, mínimo (mín.), máximo (máx.) e médio (méd.), erro padrão (ep), coeficiente de variação (cv) e número de observações (n), em Syagrus romanzoffiana (Cham.) Glassman, na floresta paludícola da Reserva Santa Genebra, Campinas, SP.

\begin{tabular}{|c|c|c|c|c|c|c|c|c|c|c|c|}
\hline \multirow[b]{2}{*}{ Estádios } & \multicolumn{5}{|c|}{ Diâmetro do estipe $(\mathrm{cm})$} & \multicolumn{5}{|c|}{ Comprimento do estipe (m) } & \multirow[t]{2}{*}{$\mathrm{n}$} \\
\hline & mín. & máx. & méd. & ep & $\mathrm{cv}$ & mín. & máx. & méd. & ep & $\mathrm{cv}$ & \\
\hline Imaturo & 7,08 & 17,83 & $12,03^{\mathrm{a}}$ & 0,80 & 24,88 & 0,11 & 2,50 & $1,42^{\mathrm{a}}$ & 0,17 & 47,07 & 14 \\
\hline Virgem & 14,64 & 22,92 & $18,64^{\mathrm{b}}$ & 0,96 & 14,55 & 3,60 & 7,50 & $5,86^{\mathrm{b}}$ & 0,52 & 25,34 & 8 \\
\hline Reprodutor & 13,05 & 28,01 & $19,41^{\mathrm{b}}$ & 0,61 & 17,72 & 6,00 & 18,00 & $11,22^{\mathrm{c}}$ & 0,45 & 22,66 & 32 \\
\hline
\end{tabular}

Letras iguais para média representam diferenças não significativas, teste Tukey, $\alpha=5 \%$ 
Tabela 4. Número de folhas e de folhas produzidas, mínimo (mín.), máximo (máx.) e médio (méd.), erro padrão (ep), coeficiente de variação (cv) e número de observações (n), em Syagrus romanzoffiana (Cham.) Glassman, na floresta paludícola da Reserva Santa Genebra, Campinas, SP.

\begin{tabular}{|c|c|c|c|c|c|c|c|c|c|c|c|c|}
\hline \multirow[b]{2}{*}{ Estádios } & \multicolumn{6}{|c|}{ Folhas.indivíduo $^{-1}$} & \multicolumn{6}{|c|}{ Folhas produzidas.indivíduo ${ }^{-1} .400 \operatorname{dias}^{-10}$} \\
\hline & mín. & máx. & méd. & ep & $\mathrm{cv}$ & $\mathrm{n}$ & mín. & máx. & méd. & ep & $\mathrm{cv}$ & $\mathrm{n}$ \\
\hline Plântula & 1 & 5 & $1,77^{\mathrm{a}}$ & 0,04 & 42,63 & 307 & 0 & 4 & $1,42^{\mathrm{a}}$ & 0,04 & 48,36 & 307 \\
\hline Juvenil 1 & 1 & 5 & $2,64^{\mathrm{b}}$ & 0,05 & 32,77 & 245 & 0 & 4 & $1,51^{\mathrm{a}}$ & 0,06 & 47,03 & 148 \\
\hline Juvenil 2 & 1 & 4 & $2,48^{\mathrm{b}}$ & 0,06 & 29,54 & 160 & 0 & 2 & $0,38^{\mathrm{b}}$ & 0,06 & 187,97 & 160 \\
\hline Imaturo & 1 & 8 & $4,29^{\mathrm{c}}$ & 0,49 & 42,69 & 14 & 0 & 3 & $0,86^{\mathrm{ab}}$ & 0,28 & 123,60 & 14 \\
\hline Virgem & 5 & 11 & $7,75^{\mathrm{d}}$ & 0,70 & 25,60 & 8 & 0 & 9 & $1,63^{\mathrm{a}}$ & 1,09 & 189,52 & 8 \\
\hline Reprodutor & 6 & 19 & $11,63^{\mathrm{e}}$ & 0,56 & 27,35 & 32 & 0 & 7 & $1,55^{\mathrm{a}}$ & 0,40 & 144,73 & 31 \\
\hline
\end{tabular}

Letras iguais para média representam diferenças não significativas, teste Tukey, $\alpha=5 \%$

que em plântula (Tab. 4). Possivelmente, em decorrência da produção de folhas mais elaboradas e do desenvolvimento do estipe, ocorreu menor produção de folhas nos estádios juvenil 2 e imaturo (Tab. 4).

A tentativa de utilizar medidas de tamanho (consideradas no presente estudo) como caráter distintivo dos estádios mostrou-se mais crítica entre os estádios virgem e reprodutor, não sendo possível distinguí-los no campo considerando-se apenas os parâmetros quantitativos (mesmo através do diâmetro basal, pois ocorreu sobreposição de tamanhos, embora as médias deste parâmetro tenham sido diferentes significativamente - Tab. 2). Adicionalmente, o estudo da população tem que envolver um tempo considerável, pois alguns indivíduos reproduziram-se em um ano e não no seguinte ou vice-versa. Apesar do tamanho auxiliar na distinção de estádios, acreditamos ser necessário um conhecimento prévio da espécie para definí-los com segurança e para que os parâmetros de tamanho tenham relação com a biologia da planta. Gatsuk et al. (1980) não incluíram palmeiras em suas observações, mas seus conceitos podem ser aplicados

Tabela 5. Comprimento da folha, mínimo (mín.), máximo (máx.) e médio (méd.), erro padrão (ep), coeficiente de variação (cv) e número de observações (n), em Syagrus romanzoffiana (Cham.) Glassman, na floresta paludícola da Reserva Santa Genebra, Campinas, SP.

\begin{tabular}{lcccccc}
\hline & \multicolumn{7}{c}{ Comprimento da folha (cm) } \\
\cline { 2 - 7 } Estádios & mín. & máx. & méd. & ep & cv & n \\
\hline Plântula & 1,0 & 47,0 & $18,32^{\mathrm{a}}$ & 0,42 & 43,94 & 362 \\
Juvenil 1 & 9,5 & 150,0 & $53,89^{\mathrm{b}}$ & 1,24 & 45,06 & 383 \\
Juvenil 2 & 7,5 & 241,0 & $91,76^{\mathrm{c}}$ & 2,73 & 47,17 & 251 \\
\hline
\end{tabular}

Letras iguais para média representam diferenças não significativas, teste Tukey, $\alpha=5 \%$ à caracterização dos estádios ontogenéticos de Syagrus romazonffiana, da mesma forma como estes têm sido reconhecidos em várias outras espécies de palmeiras (Durán \& Franco 1992; Svenning 2002; Freckleton et al. 2003; Souza et al. 2003; Souza \& Martins 2005, entre outros). Adicionalmente, em S. romazonffiana os estádios ontogenéticos mostraram-se eventos significativos da biologia da população estudada e não foram exclusivamente dependentes da idade e tamanho dos indivíduos.

\section{Agradecimentos}

À Fundação José Pedro de Oliveira, administradora da Reserva Municipal de Santa Genebra, pela permissão do acesso à área; à CAPES, pelos dois anos de bolsa de estudo, na fase inicial do projeto; ao IAC, pela possibilidade de continuar a realização do estudo.

\section{Referências bibliográficas}

Begon, M.; Harper, J.L. \& Townsend, C.R. 1996. Ecology: individuals, populations and communities. $3^{\text {rd }}$ ed. Oxford, Blackwell Sci.

Bernacci, L.C.; Goldenberg, R. \& Metzger, J.P. 1998. Estrutura florística de 15 fragmentos florestais ripários na Bacia do Jacaré-Pepira (SP). Naturalia 23: 23-54.

Bernal, R. 1998. Demography of the vegetable ivory palm Phytelephas seemannii in Colômbia, and the impact $\mathrm{f}$ seed harvesting. Journal of Applied Ecology 35: 64-74.

Bondar, G. 1964. Palmeiras do Brasil. São Paulo, Instituto de Botânica.

Bovi, M.L.A. 1998. Palmito-jerivá: Syagrus romanzoffiana (Cham.) Glassm. Pp. 262-263. In: J.I. Fahl; M.B.P. Camargo; M.A. Pizzinato; J.A. Betti; A.M.T. Melo; I.C. Maria \& A.M.C. Furlani (eds.). Instruções agrícolas para as principais culturas econômicas (Boletim 200). Campinas, Instituto Agronômico. 
Bovi, M.L.A.; Godoy Jr., G. \& Saes, L.A. 1988. Pesquisas com os gêneros Euterpe e Bactris no Instituto Agronômico de Campinas. In: Anais do $1^{\circ}$ Encontro Nacional de Pesquisadores em Palmito. Curitiba, 1987. EMBRAPA-CNPF, Documentos 19.

Carvalho, R.M.; Martins, F.R. \& Santos, F.A.M. 1999. Leaf ecology of pre-reproductive stages of the palm tree Euterpe edulis Mart. (Arecaceae). Annals of Botany 83: 225-233.

Chazdon, R.L. 1986. Physiological and morphological basis of shade tolerance in rain forest understory palms. Principes 30: 92-99.

Clancy, K.E. \& Sullivan, M.J. 1988. Some observations on seed germination, the seedling, and polyembryony in the needle palm Rhapidophyllum hystrix. Principes 32: $18-25$.

Corrêa, M.P. 1969. Dicionário das plantas úteis do Brasil e das exóticas cultivadas. v. 4. Rio de Janeiro, IBDF.

EMBRAPA - Empresa Brasileira de Pesquisa Agropecuária. 1999. Sistema Brasileiro de Classificação de Solos. Rio de Janeiro, EMBRAPA.

Fenner, M. 1987. Seedlings. New Phytol. 106 (Suppl.): 35-54.

Font-Quer, P. 1985. Diccionario de Botánica. Barcelona, Labor.

Durán, R. \& Franco, M. 1992. Estudio demográfico de Pseudophoenix sargentii. Bulletin de l'Institute Français d'Études Andines 21: 609-621.

Freckleton, R.P.; Silva-Matos, D.M.; Watkinson, A.R. \& Bovi, M.L.A. 2003. Predicting the impacts of harvesting using structured population models: the importance of density-dependence and timing of harvest for a tropical palm tree. Journal of Applied Ecology 40: 846-858.

Galetti, M. 1995. Os frugívoros da Santa Genebra. Pp. 66-69. In: H.F. Leitão Filho \& P.C. Morellato (orgs.). Ecologia e preservação de uma floresta tropical urbana. Campinas, UNICAMP.

Gatsuk, L.E.; Smirnova, O.V.; Vorontzova, L.I.; Zaugolnova, L.B. \& Zhukova, L.A. 1980. Age states of plants of various growth forms: a review. Journal of Ecology 68 : 675-96.

Ghose, M. \& Johri, B.M. 1990. Anatomy of the stems of seedling palms. Proceedings of the Indian Academy of Sciences. Plant Sciences 100: 215-223.

Glassman, S.F. 1987. Revision of the palm genus Syagrus Mart. and the other genera in the Cocos Alliance. Illinois Biological Monographs 56: 1-231.

Graf, A.B. 1986. Tropica: color cyclopedia of exotic plants and trees. $3^{\text {rd. }}$ ed. Roehrs, East Rutherford.

Henderson, A.; Galeano, G. \& Bernal, R. 1995. Field guide to the palms of the Americas. Princeton, Princeton University.

Instituto Agronômico. 1997. Cultivares elite. Campinas, Instituto Agronômico.

Joly, C.A. 1986. Heterogeneidade ambiental e diversidade de estratégias adaptativas de espécies arbóreas de mata de galeria. ACIESP (Publicação ACIESP 50): 19-38.

Kahn, F. 1986. Life forms of Amazonian palms in relation to forest structure and dynamics. Biotropica 18: 214-218.
Knevel, I.C. \& Lubke, R.A. 2004. Reproductive phenology of Scaevola plumieri; a key coloniser of the coastal foredunes of South Africa. Plant Ecology 175: 137-145.

Lawson, E.J.R. \& Poethig, R.S. 1995. Shoot development in plants: time for a change. Trends in Genetics 11: 263-268.

Leitão Filho, H.F. 1995. A vegetação da Reserva de Santa Genebra. Pp. 19-29. In: H.F. Leitão Filho \& P.C. Morellato (orgs.). Ecologia e preservação de uma floresta tropical urbana. Campinas, UNICAMP.

Lorenzi, H. 1992. Árvores brasileiras: manual de identificação e cultivo de plantas arbóreas nativas do Brasil. Nova Odessa, Plantarum.

Lorenzi, H.; Souza, H.M.; Medeiros-Costa, J.T.; Cerqueira, L.S.C. \& Behr, N. 1996. Palmeiras no Brasil: nativas e exóticas. Nova Odessa, Plantarum.

Manly, B.F.J. 1990. Stage-structured populations: sampling, analysis and simulation. London, Chapman and Hall.

Marie-Pierre, J.; Didier, A. \& Gérard, B. 2006. Patterns of ash (Fraxinus excelsior L.) colonization in mountain grasslands: the importance of management practices. Plant Ecology 183: 177-189

Mello, M.H.A.; Pedro Jr., M.J.; Ortolani, A.A. \& Alfonsi, R.R. 1994. Chuva e temperatura: cem anos de observações em Campinas. Boletim Técnico 154. Campinas, Instituto Agronômico.

Monteiro, E.A. \& Fisch, S.T.V. 2005. Estrutura e padrão espacial das populações de Bactris setosa Mart. e $B$. hatschbachii Noblick ex A.Hend. (Arecaceae) no gradiente altitudinal, Ubatuba (SP). Biota Neotropica 5: http://www.biotaneotropica.org.br/v5n2/pt/ abstract?article+BN00505022005 (Acessado em: 4/08/2006).

Moore Jr., H.E. 1961. Botany and classification of palms. American Hort. Mag. 40: 17-26.

Moore Jr., H.E. \& Uhl, N.W. 1973. The monocotyledons: their evolution and comparative biology - VI - Palms and the origin and evolution of monocotyledons. Quaterly Review of Biology 48: 414-436.

Niklas, K.J. 1992. Plant biomechanics: an engineering approach to plant form and function. Chicago, University of Chicago.

Noblick, L.R. 1996. Syagrus. The Palm Journal 126: 12-46.

Nogueira, J.B. \& Machado, R.D. 1950. Glossário de palmeiras oleaginosas e ceríferas. Rio de Janeiro, Instituto de Óleos - Ministério da Agricultura.

Parkhurst, D.F. \& Loucks, O.L. 1972. Optimal leaf size in relation to environment. Journal of Ecology 60: 505-537.

Reis, A.; Kageyama, P.Y.; Reis, M.S. \& Fantini, A. 1996. Demografia de Euterpe edulis Martius (Arecaceae) em uma floresta ombrófila densa montana, em Blumenau (SC). Sellowia 45-48: 13-45.

Sanchotene, M.C.C. 1989. Frutíferas nativas úteis à fauna na arborização urbana. Porto Alegre, Sagra.

São Paulo, Estado. 1981. Plano Cartográfico do Estado de São Paulo: Barão Geraldo. São Paulo, Secretaria de Economia e Planejamento. 
Silvertown, J.K. \& Doust, J.L. 1993. Introduction to plant biology. Oxford, Blackwell Sci.

Sist, P. 1989. Demography of Astrocaryum sciophilum, an understory palm of French Guiana. Principes 33: 142-151.

Siqueira, J.C. 1989. Considerações sobre a biologia da polinização em palmeira gerivá (Arecastrum romanzoffianum - Palmae). Acta Biologica Leopoldensia 11: 203-212.

Sokal, R.R. \& Rohlf, F.J. 1979. Biometria - principios y métodos estadísticos en la investigación biológica. Madrid, H. Blume.

Souza, A.F. \& Martins, F.R. 2005. Spatial variation and dynamics of flooding, canopy openness, and structure in a Neotropical swamp forest. Plant Ecology 180: 161-173.

Souza, A.F.; Martins, F.R. \& Bernacci, L.C. 2003. Clonal growth and reproductive strategies of the understory tropical palm Geonoma brevispatha: an ontogenetic approach. Canadian Journal of Botany 81: 101-112.

Souza, V.C.; Cortopassi-Laurino, M.; Simão-Bianchini, R.; Pirani, J.R.; Azoubel, M.C.; Guibu, L.S. \& Giannini, T.C. 1994. Plantas apícolas de São Paulo e arredores. Pp. 43-192. In: J.R. Pirani \& M. Cortopassi-Laurino (coords.). Flores e abelhas em São Paulo. São Paulo, EDUSP.
Svenning, J.C. 2002. Crown illumination limits the population growth rate of a neotropical understorey palm (Geonoma macrostachys, Arecaceae). Plant Ecology 159: 185-199.

Tomlinson, P.B. 1960a. Essays on the morphology of palms: I - germination and the seedling. Principes 4: 56-61.

Tomlinson, P.B. 1960b. Seedling leaves in palms and their morphological significance. Journal Arnold Arboretum 41: 414-428.

Tomlinson, P.B. 1971. The shoot apex and its dichotomous branching in the Nypa palm. Annals of Botany 35: 865-879.

Toniato, M.T.Z.; Leitão Filho, H.F. \& Rodrigues, R.R. 1998. Fitossociologia de um remanescente de floresta higrófila (mata de brejo) em Campinas, SP. Revista Brasileira de Botânica 21: 197-210.

Uhl, N.M. \& Dransfield, J. 1987. Genera palmarum. Lawrence, Allen.

Vandermeer, J.H. 1990. Crecimiento y supervivencia de plántulas de Welfia georgii en un bosque pluvial en la costa caribeña de Costa Rica. Revista de Biologia Tropical 38: 7-20.

Vandermeer, J.H.; Stout, J. \& Miller, G. 1974. Growth rates of Welfia georgii, Socratea durissima, and Iriartea gigantea under various conditions in a natural rainforest in Costa Rica. Principes 18: 148-154. 